\title{
PEDAGOGIA E ARQUITETURA NOS ESPAÇOS DE CONVIVÊNCIA: PROPOSTAS DE ADEQUAÇÃO AO PROJETO POLÍTICO PEDAGÓGICO DO COMPLEXO EDUCACIONAL DO BAIRRO DA JUVENTUDE
}

\author{
PEDAGOGY AND ARCHITECTURE IN THE LIVING SPACES: PROPOSALS FOR \\ ADEQUACY TO THE PEDAGOGICAL POLITICAL PROJECT OF THE \\ EDUCATIONAL COMPLEX IN THE BAIRRO DA JUVENTUDE
}

Carlos Alexandre Padilha da Silva ${ }^{1}$
Samira Casagrande
Jorge Luiz Vieira $^{2}$

\begin{abstract}
RESUMO
O presente artigo apresenta as ações desenvolvidas pelo projeto de extensão, realizado no Bairro da Juventude em parceria com os cursos de Arquitetura e Urbanismo e Pedagogia, da Universidade do Extremo Sul Catarinense- UNESC, sob o título "Complexo Educacional Bairro da Juventude - Criciúma/SC: Revitalização e adequação dos espaços físicos comunitários ao projeto pedagógico da instituição". Este trabalho aborda a contribuição da equipe extensionista da UNESC, formada por docentes e discentes bolsistas dos cursos de Arquitetura e Urbanismo e de Pedagogia, para a criação de novos espaços físicos aliados a uma concepção pedagógica de educação integral, que a Instituição Bairro da Juventude adota, mas que pretende ampliar a partir da revisão do seu Plano Político Pedagógico - PPP. A metodologia compreendeu reuniões semanais com as equipes das duas instituições, que ora reuniam-se nas dependências da UNESC, ora no Bairro da Juventude. Paralelamente, foram realizadas diversas visitas de campo, em distintos horários, para se avaliar as formas de apropriação dos espaços de convivência e se estes correspondiam às expectativas de ensino-aprendizagem inseridas no PPP. Do encontro das expectativas elencadas pela equipe de professores do Bairro da Juventude e dos levantamentos de campo realizados pela equipe da UNESC, foi possível se traçar algumas diretrizes de qualificação dos espaços de convivência em relação aos objetivos pedagógicos pretendidos. Com este trabalho foi possível entender a relação entre espaço, concepção pedagógica e os processos de ensino, pesquisa e extensão.
\end{abstract}

Palavras chave: Bairro da Juventude, Readequação física, Concepção pedagógica, Transformação Social.

\footnotetext{
ABSTRACT

${ }^{1}$ Graduando de Pedagogia, UNESC, alexandregauderio@ hotmail.com.

${ }^{2}$ Mestre em Educação, UNESC sca@unesc.net

${ }^{3}$ Doutor em Arquitetura, UNESC jov@unesc.net
}

This article presents the actions developed by the extension project, carried out in Bairro da Juventude in partnership with the Architecture and Urbanism and Pedagogy courses, from the Universidade do Extremo Sul Catarinense - UNESC, under the title "Complexo Educacional Bairro da Juventude - Criciúma / SC: Revitalization and adaptation of the physical community spaces to the educational project of the 
institution". This work addresses the contribution of the UNESC extension team, formed by teachers and scholarship students from the Architecture and Urbanism and Pedagogy courses, for the creation of new physical spaces combined with a pedagogical concept of integral education, which the Bairro da Juventude Institution adopts, but which it intends to expand based on the revision of its Political Pedagogical Plan - PPP. The methodology comprised weekly meetings with the teams of the two institutions, which sometimes met at UNESC's facilities, sometimes in the Bairro da Juventude. In parallel, several field visits were made, at different times, to assess the forms of appropriation of living spaces and whether these corresponded to the teaching-learning expectations inserted in the PPP. From the meeting of the expectations set by the team of teachers from Bairro da Juventude and the field surveys carried out by the UNESC team, it was possible to outline some qualification guidelines for living spaces in relation to the intended educational objectives. With this work it was possible to understand the relationship between space, pedagogical conception and the teaching, research and extension processes.

Keywords: Bairro da Juventude, Readjustment of physical space, pedagogical conception, social transformation.

\section{INTRODUÇÃO}

Este artigo apresenta as ações realizadas no desenvolvimento do projeto de readequação dos espaços do Complexo Educacional Bairro da Juventude, com base em uma teoria pedagógica que contempla a formação dos estudantes em uma dimensão integral. Esse projeto de extensão surgiu a partir de uma necessidade concreta, apresentada pela Coordenação Pedagógica da instituição de ensino Bairro da Juventude (BJ), em 2017, ao Curso de Arquitetura e Urbanismo da UNESC.

Participaram do projeto bolsistas e professores dos cursos de Arquitetura e Urbanismo e de Pedagogia da UNESC. Do Bairro da Juventude, participaram diretamente o coordenador de projetos, o diretor geral, assim como três profissionais da coordenação pedagógica e, indiretamente, o corpo docente e representantes discentes da instituição. O projeto visou propiciara revisão e elaboração integrada do Plano Diretor Participativo (PDP) e do Projeto Político Pedagógico (PPP) do complexo educacional Bairro da Juventude , para revitalização e adequação dos espaços de convivência, atendendo os princípios e diretrizes da proposta pedagógica da instituição . Dessa forma, buscou-se estabelecer parceria com a comunidade educacional Bairro da Juventude para atuação de forma integrada entre o Plano Diretor Participativo (PDP) do seu campus e as diretrizes do Plano Político Pedagógico (PPP). 

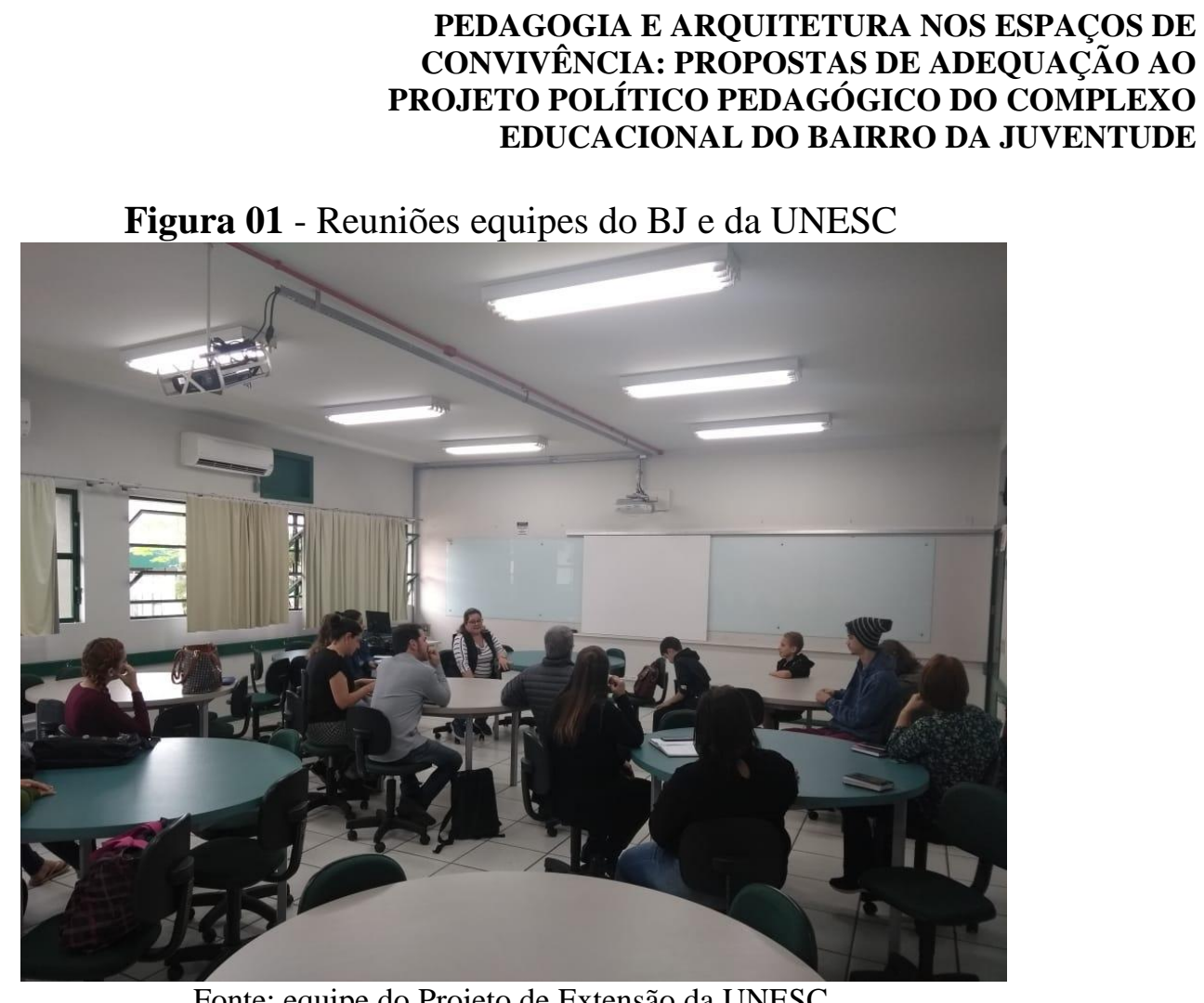

Nas discussões realizadas durante os encontros (Fig. 01), a equipe do projeto procurou promover a participação efetiva da comunidade escolar, assim como desenvolver atividades interdisciplinares entre o curso de Arquitetura e Urbanismo e o curso de Pedagogia da UNESC, envolvendo bolsistas, professores, vinculando a extensão com o ensino e a pesquisa. É nessa relação entre estudo, espaço e concepções que o projeto fez-se interdisciplinar pelos conhecimentos específicos de cada área e entre as áreas de conhecimento de Arquitetura e Urbanismo e de Pedagogia.

A construção de uma prática interdisciplinar, segundo Fazenda (2012, p.82), requer o movimento dialético "[...] atitude de envolvimento e comprometimento com os projetos e com as pessoas nele envolvidas [...]". Nessas relações de compromisso com a comunidade, os envolvidos no processo vão se constituindo pesquisadores, pois “Aprender a pesquisar, fazendo pesquisa, é próprio de uma educação interdisciplinar [...]" (FAZENDA, 2012, p. 88).

A partir da pesquisa, o grupo discutiu a aplicação de métodos que facilitem o diálogo com a comunidade educacional do Bairro da Juventude, produzindo dessa maneira, transformações entre a equipe extensionista e a comunidade, revertendo o estudo em melhoria do processo de ensino-aprendizagem das duas instituições envolvidas. 
A proposta foi pensar na construção de um novo formato de espaços integrados, que extrapole o enquadramento convencional entre quatro paredes da sala de aula e, junto com ele, uma concepção pedagógica que acompanhe este projeto arquitetônico inovador, que procura vincular as atividades de ensino-aprendizagem da sala de aula tradicional à extensão do espaço de convívio comunitário da escola. Nesta concepção, se procura favorecer o protagonismo, permitindo que o aluno se reconheça em seu contexto histórico cultural, que aprenda a se comunicar, ser criativo, analítico, crítico, participativo, aberto ao novo, colaborativo e responsável.

\section{CONTEXTUALIZANDO O BAIRRO DA JUVENTUDE}

O Complexo Educacional Bairro da Juventude está localizado na cidade de Criciúma, no Sul do Estado de Santa Catarina,é uma instituição que possui um forte caráter social no município. Seu surgimento se deu com o objetivo de amparar e oferecer educação às crianças carentes no município de Criciúma. Atualmente, a instituição tem como intuito promover e oportunizar a transformação social de crianças, adolescentes e de suas famílias por meio da educação e da assistência social.

A instituição conta com cerca de $11.400,00 \mathrm{~m}^{2}$ de área construída sobre um terreno de cerca de 4,37 hectares. Uma prioridade atual da instituição é a revisão do Plano Diretor Participativo (PDP) do campus e sua adequação ao Projeto Político Pedagógico (PPP), que está em processo de discussão pela equipe docente. Desse modo, o Curso de Arquitetura e Urbanismo buscou parceria com o Curso de Pedagogia, visando promover a interdisciplinaridade. Compreende-se que promover a interdisciplinaridade no ensino superior, entre cursos de áreas diversas, através de ações de cunho social, contribui para a ampliação dos pontos de vista dos envolvidos, discentes, docentes e equipe pedagógica. A instituição atualmente não assume a condição de escola integral, pois não conseguiu integrar às singularidades humanas às múltiplas possibilidades de aprendizagem que fundamentam a proposta desenhada pelos pioneiros da educação brasileira, no entanto, mostra-se entusiasta desta ideia.

Os espaços pedagógicos da escola (salas de aula, quadra de esporte, espaço de convívio social) encontram-se com desarticulações localizadas e alguns espaços coletivos fragmentados, por conta do seu processo de crescimento espontâneo e também devido à falta de um planejamento arquitetônico, que leve em conta o desenvolvimento 


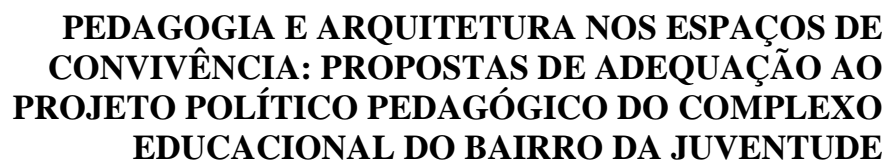

integral dos indivíduos. Martins e Gonçalves (1914, p. 623) apontam que o espaço pouco atrativo, tais como paredes acinzentadas, carteiras enfileiradas, ausências de bancos nas áreas livres e outros, raramente contribuem para o desenvolvimento físicomotor, intelectual e afetivo da criança. Neste contexto, reafirma-se o que esses e outros autores vêm apontando: o espaço também educa.

Por outro lado, pensar em ambientes construídos e dimensionados, a partir de uma concepção pedagógica interacional, requer espaços mais flexíveis, humanizados, e que sirvam de inspiração para professores e alunos. É nesse contexto que a equipe extensionista dos cursos de Arquitetura e Urbanismo e de Pedagogia da UNESC, elaborou este projeto.

Conhecer as diretrizes propostas no Projeto Político Pedagógico (PPP) do Bairro da Juventude foi o primeiro passo para que se pudesse entender o funcionamento da estrutura física e pedagógica da instituição, analisando possíveis adequações e principalmente, articular o espaço físico aos princípios filosóficos do documento. Como resultado deste estudo, aliado à observação de como se dava a apropriação dos espaços por parte dos alunos, funcionários e professores, em diferentes horários e atividades, foi possível construir uma maquete (Fig. 03)evidenciando os espaços construídos e as adequações projetadas a partir da análise e desejos dos seus usuários. Assim, a ideia era permitir que os alunos, professores e comunidade escolar percebessem o sentido que o espaço tem para sua formação e a criação de ambientes humanizados e flexíveis a diversas possibilidades de interação de atividades formativas para uma formação crítica, criativa e socialmente integrada.

Figura 02: Sala de aula do Ensino Fundamental: carteiras enfileiradas

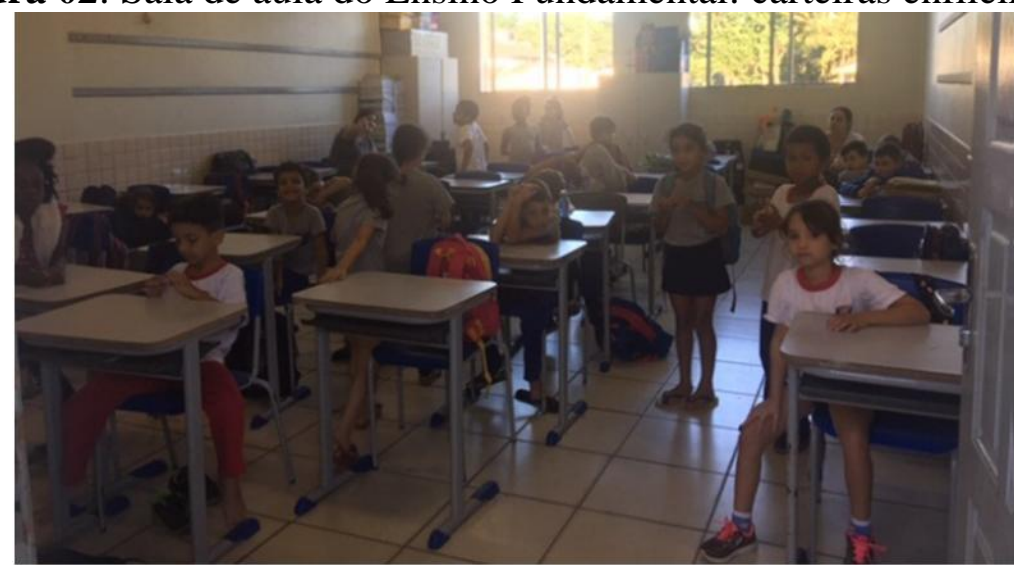

Fonte: CESCONETO, 2019, p. 40 
Figura 03: Maquete física esc. 1/250 - elaborada pela equipe de Arquitetura da UNESC

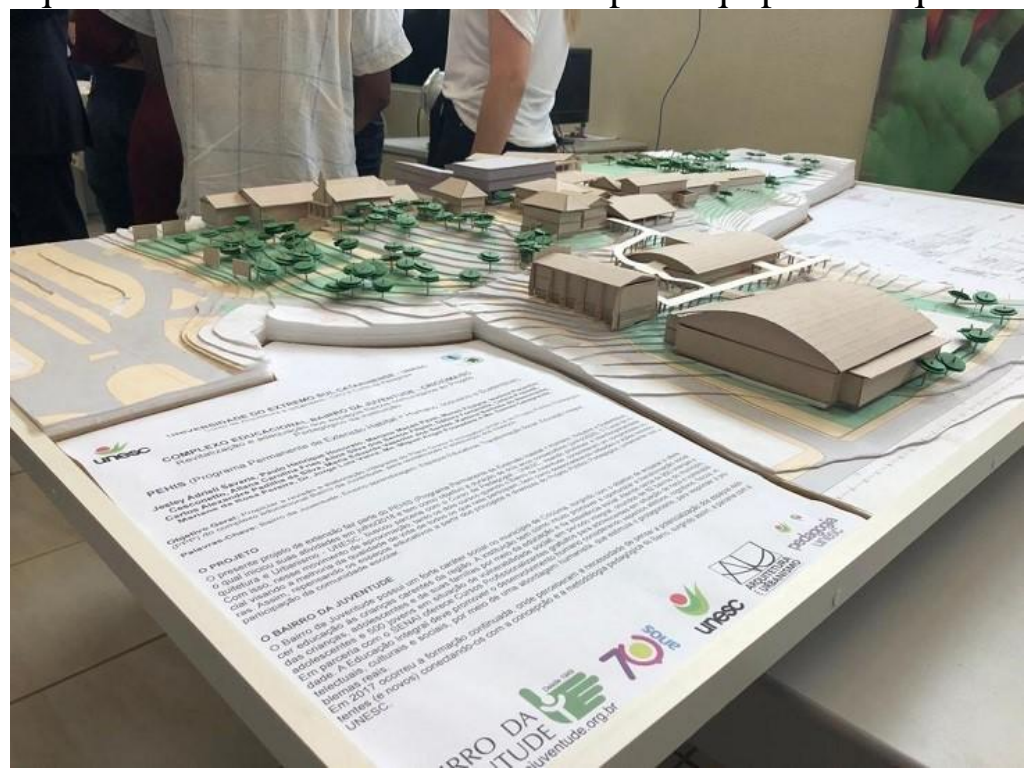

Fonte: equipe do Projeto de Extensão da UNESC

No entanto, entende-se que a escola enquanto espaço de socialização e integração de diferentes sujeitos com sonhos e desejos peculiares a sua idade, são singulares, mas também plurais quando se juntam e se organizam em um bem comum. Contudo, é preciso mais que um espaço arquitetônico, é preciso que o ambiente escolar seja acolhedor, dando a criança e jovem a sensação de segurança e bem-estar, tanto físico como emocional. Assim, é possível pensar nesse espaço como promovedor do processo de ensino-aprendizagem, mas também como construtor de elementos importantes da subjetividade, como o desenvolvimento cognitivo, afetivo, interativo, simbólico e estético (GONÇALVES, 2018).

É certo que este ambiente não é só formado de estudantes, e, por isso é notável que ele precisa também ser pensado para aqueles que trabalham nele, tais como, professores, merendeiras, pessoal do administrativo, gestores e outros profissionais. Nesse sentido, o ambiente escolar foi projetado de forma que permita o conforto e a segurança, mas também que seja humanizador e adequado ao desenvolvimento de diferentes atividades para aqueles que, também, ali trabalham.

\section{OUTROS OLHARES PARA O ESPAÇO FÍSICO}

Acredita-se que o espaço está sempre se recriando, ganhando novos sentidos à medida que os grupos que nele convivem também vão se modificando. E, ao mesmo 


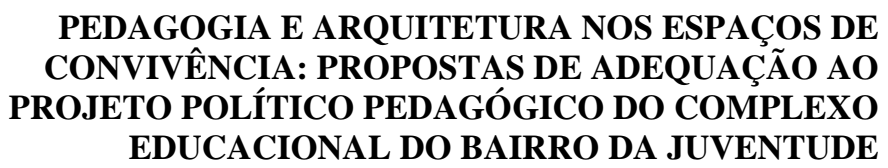

tempo, a utilização deste espaço deve estar articulada com as intenções pedagógicas. Estas intenções pedagógicas são baseadas na educação integral, em que se procura garantir o desenvolvimento do aluno em sua totalidade, propiciando o seu pleno desenvolvimento. "O que se pretende com a educação integral é desenvolver os alunos de forma completa, em sua totalidade" (ZEBINI, 2014, p.01).

De acordo com o Art. 206da Constituição Federal do Brasil (1988):

A educação, direito de todos e dever do Estado e da família, será promovida e incentivada com a colaboração da sociedade, visando ao pleno desenvolvimento da pessoa, seu preparo para o exercício da cidadania e sua qualificação para o trabalho. (BRASIL, 1988, CRF, Art. 206).

Após ocorrer diversas discussões sobre a educação no país, ao longo dos anos, ficou evidente para a sociedade a importância da escola na formação da criança e do adolescente. Na expressão de Anísio Teixeira (1961, p. 197,apud Moll, 2013, p. 296): "Já não se trata de escolas e salas de aula, mas de todo um conjunto de locais em que as crianças se distribuem entregues às atividades de 'estudo', de 'trabalho', de 'recreação', de 'reunião', de 'administração', e de vida e de convívio no mais amplo sentido desse termo".

Para que ocorra a readequação dos espaços existentes na instituição, foi necessário considerar que o espaço, por si só,representa uma situação de aprendizagem e que é composto por elementos físicos e humanos que são apropriados pelas relações que nele acontecem. Os espaços transmitem mensagens, comunicam formas de ver, sentir, dizer, narrar e significar tudo que atravessa o universo escolar. Para Frago e Escolano (1998), a escola como instituição ocupa um espaço e um lugar e, como tal, possui uma dimensão educativa. "O espaço não é neutro. Sempre educa" (FRAGO; ESCOLANO, 1998, p. 75)

De acordo com Martins e Gonçalves (2014,p.623):

\footnotetext{
Os espaços da escola deveriam dar condições para estimular as capacidades físicas (força, velocidade, flexibilidade, destreza, entre outras) e promover as habilidades motoras (correr, saltar, chutar, pular, arremessar, receber, driblar, quicar, entre outras) dos alunos, e também favorecer as relações pautadas nos valores éticos e sociais que podem se estabelecer nos referidos espaços. Tal preocupação não se limita somente aos espaços externos, mas também aos outros espaços aos quais as crianças têm acesso, tais como sala de aula, corredores, áreas cobertas, áreas de circulação e espaços utilitários (banheiros, lavatórios e refeitório). Estes também fazem parte do universo de espaços que as crianças utilizam no dia a dia da educação infantil.
} 
O estudante se identifica com o espaço por elementos de sua própria cultura, através de experiências gratificantes ou não, que ocorrem no local e nas trocas nas relações entre os pares que ocupam esse mesmo ambiente. Dessa forma, ocorre a apropriação do espaço pelos sujeitos, na medida que vão criando vínculos com a escola, vão construindo subjetividades que irão influenciar no comportamento social dos estudantes.

Pol (1996, p. 55-56) salienta que a escola já se utiliza da apropriação do espaço sem se dar conta, no momento em que as crianças veem projetadas nas paredes, seus desenhos e trabalhos como parte da decoração do ambiente. O autor ressalta que os objetivos dessa apropriação são compostos por dois fatores: o psicológico e o pedagógico, sendo que o psicológico reforça a auto-imagem frente a si e aos demais e o pedagógico desenvolve o social e o comunitário a partir da criação.

Essa apropriação se dá na medida em que o espaço adquire um caráter de finalidade educacional. $\mathrm{O}$ estudante precisa se sentir pertencente desse espaço, ele deve fazer parte da sua identidade e o local em que ele se prepara para se inserir no mundo dos adultos. É nesse sentido que a Pedagogia e a Arquitetura se aproximam, para pensarem ambientes multifuncionais, ou seja, ambientes que se caracterizam como mediadores da aprendizagem, que mobilizem professores e estudantes a criarem estratégias que favoreçam práticas cooperativas de apropriação de conhecimentos. Assim, o espaço escolar se assume como elemento ativo da aprendizagem.

Gonçalves (2018) nos traz que a psicologia ambiental pode responder a essas questões. Em sua tese, a autora aponta que o espaço da sala de aula deve ser acolhedor e agradável para as pessoas que estão nele, desde a disposição dos móveis em um formato de círculo, a fim de possibilitar a interação e promover a autonomia, e não mais no formato enfileirado, com o professor à frente se portando como o dono do saber. Sentir pertencente ao lugar é uma demonstração de que este não amedronta, mas para que isso aconteça o espaço precisa ser apropriado.

A identidade do lugar se forma com o decorrer da apropriação do espaço. Essa identidade se compreende com o sentir e, ao modificar um espaço, associam-se a ele características físicas, sociais, psíquicas e culturais. No momento em que o sujeito se apropria de um lugar, e com o passar do tempo deixa sua marca e o transforma, colocando objetos com os quais se identifica, tem início o processo de reapropriação 
(GONÇALVES, 2007, p. 22-23).

É um desafio pensar em um ambiente que permita que os sujeitos que o ocupam, adequem à sua personalidade. Essa reapropriação irá contribuir no seu processo de desenvolvimento e nos processos de aprendizagem. A identidade aqui é levada ao espaço em que esse indivíduo terá acesso aos processos de afeto, cognição e interação com o meio (GONCALVES, 2007, p.29-30).

Sabe-se que fatores sociais, familiares e econômicos influenciam na vida dos estudantes, ampliando ou restringindo suas possibilidades. Por isso, o espaço escolar deve ser emancipador para os sujeitos se desenvolverem integralmente no ambiente educacional.Pinto (2003), em seu estudo sobre a condição social do brincar na escola, partindo do ponto de vista da criança, ressalta que, quando a criança não participa da organização do tempo e do espaço da escola, pode dificultar a sua apropriação, e até influenciar o seu comportamento expressivo-motor, cognitivo, afetivo, ético e estético.

É preciso estabelecer harmonia entre o corpo, a alma e o caráter dos indivíduos, nos diferentes períodos de desenvolvimento em que se encontram. Da mesma forma, é preciso valorizar o uso de materiais naturais e o contato dos alunos com elementos da natureza. Essa discussão sobre a proteção do meio ambiente, junto com a consciência ecológica irá influenciar no processo educativo, e na relação da criança com o ambiente natural e o ambiente construído, sabendo que a construção escolar deve interagir e se harmonizar com esse ambiente. Dessa forma, deve-se construir uma visão interacionista:

\footnotetext{
"A educação ambiental precisa estar conectada ao entendimento de economia, saúde, educação e cidadania. As crianças devem entender que elas são parte de um delicado ecossistema e ter conhecimento das conseqüências positivas que advirão para todo o planeta, por exemplo, caso elas tornem seu pátio escolar verde" (FEDRIZZI, 1999, p. 15).
}

Essa ótica interacionista vai de encontro ao conceito de sustentabilidade. Acentua a melhoria da qualidade de vida com uma consciência de respeito à vida. Essa visão nos diz que o conhecimento é o resultado entre a bagagem hereditária de um indivíduo e o meio em que ele vive. Por isso, é preciso pensar na arquitetura ao mesmo tempo em que se desenvolve um olhar sobre o macro.

Anísio Teixeira acreditava que, pelo "gesto" da arquitetura moderna - o gesto gerando o sentimento - os prédios escolares pudessem "comunicar a educação" 
(TEIXEIRA, 1951, p. 175). Apesar de ter sido escrito há décadas atrás, este pensamento ainda é inovador, pois acredita que a arquitetura pode transmitir uma nova maneira de educar, isso através da Arquitetura e Urbanismo aliado a uma concepção pedagógica fundamentada na educação integral.

E, de fato, com as suas escolas, com os seus prédios especialmente projetados, com os seus programas específicos para cada tipo de escola, Anísio dava-nos o exemplo de que, também, por meio da arquitetura era possível criar uma nova concepção de educação. É nessa direção que o projeto de readequação dos espaços do complexo educacional Bairro da Juventude busca caminhar. E nesse sentido, o Plano Diretor Participativo (PDP) se constituiu no elemento-chave para propor as adequações físicoespaciais às demandas do PPP, relativas ao processo de interação socioeducativa por este preconizado. Partiu-se assim do entendimento de que os espaços físicos, na sua totalidade, devem contribuir para o processo de ensino-aprendizagem em todas as suas dimensões, seja no âmbito do indivíduo, seja no âmbito de sua interação coletiva, como locus de se conhecer, se reconhecer e se projetar, por meio das mais diversas atividades que o ambiente escolar pode oferecer ao desenvolvimento cognitivo, sensitivo e criativo.

\section{PROCEDIMENTOS METODOLÓGICOS}

A organização dos trabalhos, inicialmente, partiu de um planejamento conjunto das atividades, envolvendo os participantes da UNESC e do Bairro da Juventude. Nas primeiras reuniões, foram definidas a agenda e a programação de atividades do primeiro semestre. E a cada semestre, foram se avaliando os objetivos alcançados e os que deveriam ser complementados ou revistos. $\mathrm{O}$ desenvolvimento das atividades partiu de uma sequência de reuniões conjuntas que, depois, se desdobrou em reuniões setoriais, envolvendo os participantes por área - pedagogia e arquitetura. E, posteriormente, voltou-se para as reuniões conjuntas.

A primeira etapa de reuniões conjuntas permitiu a cada grupo de participantes compreender as diretrizes e objetivos do Projeto Político Pedagógico (PPP) e as condições dos espaços físicos frente a estas diretrizes e objetivos. Nesse momento, se discutiu em profundidade o PPP e se levantou e se avaliou a estrutura física do Complexo Educacional. Foi um momento muito rico, de muito levantamento e de muito 


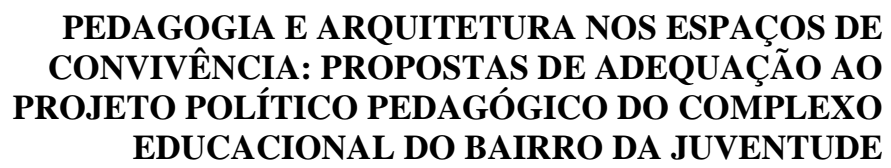

debate.

A segunda etapa se deu por reuniões de equipes específicas - professores do Bairro, equipe pedagógica e equipe de Arquitetura. Esta etapa foi de lançamento de propostas de ajustes do PPP e de formulação de um partido para o Plano Diretor Participativo (PDP). Foi a etapa de imersão e síntese das equipes, pois mesmo trabalhando setorialmente, o processo se manteve interdisciplinar, com trocas frequentes entre cada grupo. E a etapa final foi de se reunir as proposições e ajustá-las para a finalização do Plano Diretor do espaço físico, de acordo com as necessidades espaciais requeridas a partir dos ajustes realizados no PPP.

No processo de desenvolvimento do projeto de extensão, foram definidos procedimentos metodológicos visando a organização das atividades de cada equipe, que foram divididas em: Equipe da direção do Bairro; Equipe Pedagógica e Equipe de Arquitetura. Vale salientar que em todas as equipes tinha-se representantes do Bairro da Juventude. As reuniões eram realizadas semanalmente com as pessoas partícipes do projeto, que ora reuniam-se nas dependências da UNESC, ora no Bairro da Juventude.

Foi possibilitado a realização de momentos diferenciados de encontros, pensando a especificidade de cada área de conhecimento envolvida. Através destes encontros, os integrantes socializavam os resultados das reuniões realizadas pelas diferentes áreas de conhecimento (Figura 04).

Figura 04: Reuniões multidisciplinar de socialização dos trabalhos

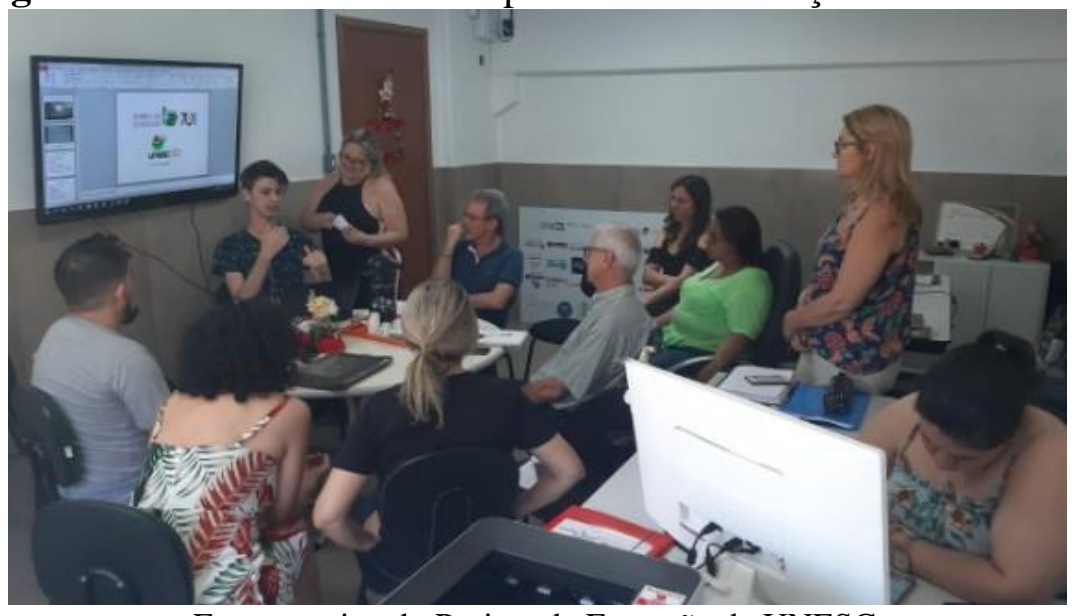

Fonte: equipe do Projeto de Extensão da UNESC

As equipes Pedagógicas e de Arquitetura realizaram uma pesquisa de campo no complexo educacional, entrevistando alunos, professores e funcionários do Bairro da 
Juventude, com o objetivo de saber dos entrevistados qual a percepção que tinham do ambiente e o que acrescentariam de novo, tanto nos aspectos arquitetônico, como no pedagógico. Esses dados serviram para tomadas de decisões no aspecto estrutural da Escola.

Após analisar o Projeto Político Pedagógico do Bairro da Juventude, a equipe pedagógica percebeu a necessidade de atualizar alguns conceitos que estavam no documento. Assim, utilizou-se das reuniões pedagógicas, já constadas em seu planejamento anual, para ouvir sugestões de melhorias e readequações nos espaços de aprendizagens de seus professores.

Ao mapear as prioridades apresentadas pelos professores do Bairro da Juventude, foi possível atualizar a maquete física sugerida e acadêmicos da UNESC, com base em um plano de readequação dos espaços construídos, representado por meio de desenhos e de uma maquete digital (Fig. 05). Entende-se que o conhecimento não é estanque, ele transita nas diversas áreas, e possibilitar, por meio de um projeto de extensão, a reflexão crítica dos participantes sobre o papel social desempenhado nesses projetos, é essencial para uma formação qualificada. Sem contar a experiência enriquecedora das atividades interdisciplinares entre Arquitetura, Pedagogia e Escola Bairro da Juventude.

Esse projeto de extensão, ganhou repercussão na mídia impressa e falada local, por se tratar de um projeto que foi desenvolvido numa instituição de grande prestígio social no município de Criciúma. Vale destacar, que nesse momento foi apresentado à sociedade a conclusão parcial do projeto, por meio das maquetes física e digital.

Outrossim, o projeto não foi concluído em sua totalidade por razões da pandemia, que acometeu o município, o país e o mundo. Nesse momento, o indicativo era para não ter aglomerações, ou seja, as reuniões precisaram ser via remoto. Dessa forma, foi possível concluir com as sugestões colocadas na maquete física. 
Figura 05: Maquete digital. Em vermelho os espaços a serem readequados ou ampliados

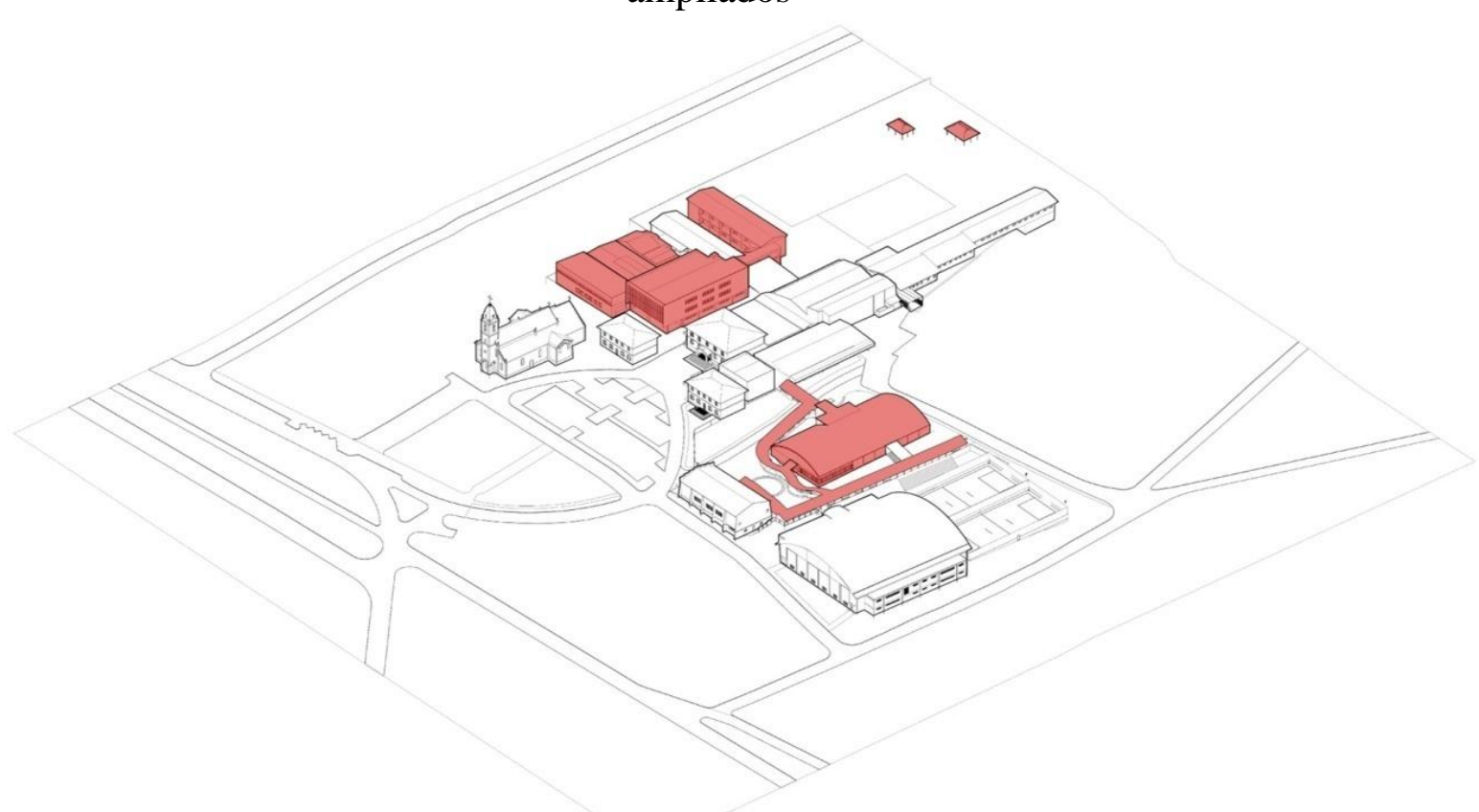

Fonte: equipe do Projeto de Extensão da UNESC

\section{CONCLUSÃO}

De maneira geral, podemos dizer que a educação integral significa uma ação educacional que envolve dimensões variadas e abrangentes da formação dos indivíduos. Os vínculos entre educação escolar, natureza, cultura e valores sociais, formação de cidadania e formação para o trabalho, foram, em determinados momentos insatisfatórios e levaram ao desenvolvimento de propostas de educação integral. A escola, oferecendo estas possibilidades aos alunos de forma correta, estará mais apta a alcançar uma educação de qualidade para formar cidadãos críticos, com perspectivas em suas vidas podendo chegar ao tão sonhado sucesso.

É nessa perspectiva que se acredita que o desenvolvimento do projeto de readequação dos espaços pode contribuir para uma concepção pedagógica que desenvolva o aluno em todas as suas dimensões. O estudo desenvolvido, ao longo do projeto, poderá ser de extrema contribuição no processo de ensino-aprendizagem, como resultado de um planejamento das pessoas envolvidas com o projeto.

Até o presente momento, ele foi apresentado para a comunidade acadêmica 
através da escolha do projeto como tema de Trabalho de Conclusão de Curso (TCC) para os cursos de Pedagogia e Arquitetura e Urbanismo, assim como apresentação em seminário de educação, todos realizados na Universidade do Extremo Sul Catarinense UNESC. A imprensa regional e estadual também teve acesso ao projeto, através de uma apresentação realizada no Bairro da Juventude em dezembro de 2019. Dessa maneira, o projeto deverá contribuir no desenvolvimento local, regional e estadual.

O resultado é consequência da referência como um todo no aspecto cognitivo e interpessoal com tantas coisas externas contrárias, só vai haver mudança profunda com o envolvimento de todos que estão trabalhando no projeto e também da equipe gestora. Outro aspecto que foi analisado, durante todas as propostas desenvolvidas, foi a de que são de interesse dos alunos e professores, uma vez que eles participaram das discussões sugerindo a construção de um novo formato de sala de aula, tornando-o mais próximo de sua realidade possível. Se a pretensão é de mudanças, elas devem partir dos profissionais,os quais têm que se reeducar, se humanizar e se aprimorar sempre. Uma educação de qualidade é uma relação capaz de acolher e transformar, recebendo pessoas que portam sonhos e que querem mudar, crescer, expandir sua vida interior e sua capacidade de agir sobre o mundo, sem estabelecer uma barreira.

\section{REFERÊNCIAS:}

CRICIÚMA. Bairro da Juventude: Projeto Político Pedagógico. 2019.

BRASIL. Constituição da República Federativa do Brasil de 1988. Disponível em: <http://www.planalto.gov.br/ccivil_03/constituicao/constituicao.htm>. Acesso em: 29 de abr. 2020.

FAZENDA, Ivani Catarina Arantes. Interdisciplinaridade: História, teoria e pesquisa. 18a ed. Campinas, SP: Papirus, 2012.

FEDRIZZI, Beatriz. "Paisagismo no pátio escolar". Porto Alegre: Editora da Universidade/UFRGS,1999.

FRAGO, A. V.; ESCOLANO, A. Currículo, espaço e subjetividade: a arquitetura como programa. Tradução de: VEIGA NETO, Alfredo. Rio de Janeiro: DP\&A, 1998.

GONÇALVES, M. T. O processo de apropriação do espaço na cidade de Criciúma-SC. Relatório do GIPMAUR. Criciúma, SC: Unesc, 2018. 
GONÇALVES, T. M. Cidade e poética: um estudo de psicologia ambiental sobre o ambiente urbano. Ijuí, RS: UNIJUÍ, 2007.

MARTINS, Rudnei Joaquim; GONCALVES, Teresinha Maria. Apropriação do espaço na pré-escola segundo a psicologia ambiental.Psicol. Soc., Belo Horizonte , v. 26, n. 3, p. 622-631, Dec. 2014. Available from <http://www.scielo.br/scielo.php?script=sci_arttext\&pid=S0102$71822014000300011 \& \operatorname{lng}=$ en\&nrm=iso > . Acesso em: 16 de jun. 2020. https://doi.org/10.1590/S0102-71822014000300011

MOLL, Jaqueline; LECLERC, Gesuína de Fátima Elias. Diversidade e Tempo integral: A garantia dos direitos sociais. Revista Retratos da Escola, Brasília, v. 7, n. 13, p. 291304, jul/dez. 2013.

PINTO, M. R. B. (2003). A condição social do brincar na escola: o ponto de vista da criança. Dissertação de Mestrado, Programa de Pós-graduação em Educação, Universidade Federal de Santa Catarina, Florianópolis, SC.

POL, E. La apropiacióndelespacio. In: ÍÑIGUEZ, L.; POL, E. (orgs.), Cognición, representación y apropriacióndelespácio. ColecciónMonografiesPsico-SocioAmbientals, v. 9, p. 45-62. Barcelona: Publications de laUniversitat de Barcelona, 1996.

TEIXEIRA, A. S. Um presságio de progresso. Habitat, São Paulo, v. 4, n. 2, p. 175, 1951. Disponível em: $<$ http://www.bvanisioteixeira.ufba.br/artigos/pressagio.html $>$. Acesso em: 29 de abr. 2020.

ZEBINI, Daniele. Ensino Integral. O que é educação integral? Disponível em:http://educarparacrescer.abril.com.br/politica-publica/educacao-integral624287.shtml.

Acesso em:29 de abr. 2020. 